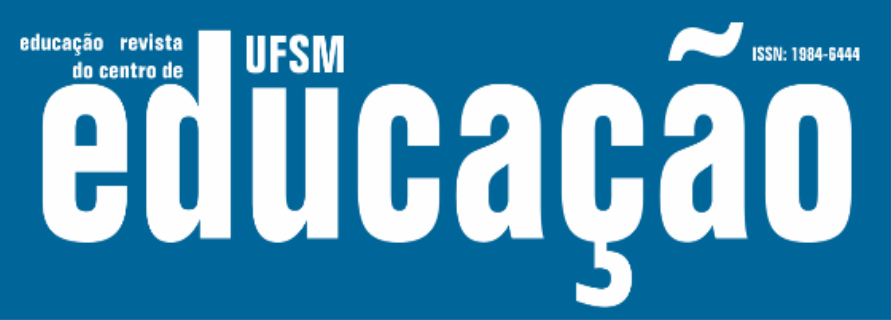

ISSN: 1984-6444 | http://dx.doi.org/10.5902/1984644439110

\title{
Um olhar sobre a educação de infância em Cabo Verde
}

\author{
A glance at the preschool in Cabo Verde
}

\section{Catarina Fernandes Delgado}

Doutoranda na Universidade de Extremadura Espanha

Docente na Faculdade de Educação e Desporto da Universidade de Cabo Verde, Cruz Grande Santa Catarina, Cabo Verde.

Catarina.delgado@docente.unicv.edu.cv, kat261@hotmail.com

Recebido em 26 de julho de 2019

Aprovado em 30 de outubro de 2019

Publicado em 17 de dezembro de 2019

\section{RESUMO}

O presente estudo tem como objetivo compreender a realidade da educação de infância em Cabo Verde, centrando-se nas políticas e nas práticas. No que tange às técnicas de recolha de dados optamos pela triangulação, usando técnicas qualitativas e quantitativas. $O$ estudo permitiu-nos concluir que em Cabo Verde, a educação de infância teve o seu aparecimento oficial com a publicação da Lei de Bases do Sistema Educativo em 1990 e que o mesmo aparece como subsistema educativo. Relacionado a prática verificamos há uma cobertura de mais de $70 \%$ e existência de vários jardinsde-infância em diversas localidades do país, além de existirem muitas perspetivas que permitem a sua expansão e organização. Por outro lado, verificamos lacunas a nível da formação de profissionais de infância e não só, os que estão formados estão noutro subsistema escolar. Constatamos uma baixa capacitação dos profissionais, ou seja, na sua maioria tem habilitações baixas que não Ihes permite ter uma prática fundamentada. A educação pré-escolar carece de normativos claros relativos ao recrutamento do pessoal docente, abertura de jardins-de-infância e dentre outros aspetos.

Palavras-chave: Educação Pré-Escolar; Políticas e Práticas.

\section{ABSTRAT}

The present study aims to understand the reality of preschool in Cabo Verde, focusing on policies and practices. In which concerns the data collection, we chose data triangulation, using both qualitative and quantitative approaches. The study allows us to conclude that preschool in Cabo Verde officially emerged in 1990, by the publication of Basic Law on Education, it appears as an educational subsystem. In which regards to the practices, we noticed there is more than $70 \%$ of coverage in many kindergartens 


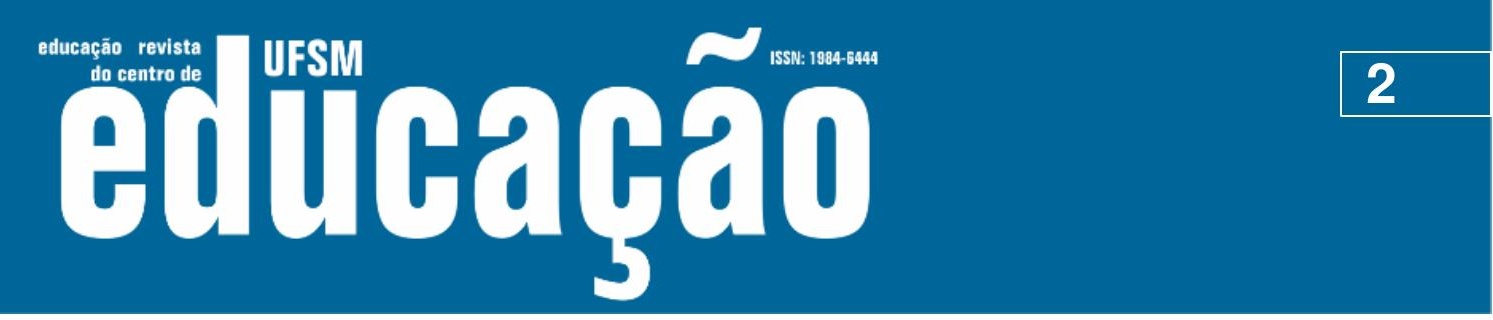

ISSN: 1984-6444 | http://dx.doi.org/10.5902/1984644439110

in several communities across the country, and there are many perspectives that allow its organization and extension.

On the order hand, we verified weakness related to the training of preschool staff and other issues, those who are trained to teach are performing in another educational subsystem. We noticed a weak training of employees, that is, most of them have low skills which do not allow them to have a solid background practice.

Preschool needs clear regulating acts in which concerning to recruitment of teaching staff, the opening of kindergartens and other issues.

Keywords: Preschool Education, Policies and Practices.

\section{Introdução}

Cabo Verde é um pequeno país, formado por 10 ilhas e 5 ilhéus de origem vulcânica, situando-se a cerca de $500 \mathrm{~km}$ a oeste da costa africana, no Oceano Atlântico. As ilhas distribuem-se por dois grupos, Sotavento e Barlavento.

Na ilha de Santiago (grupo Sotavento) situa-se a capital do país, Praia e os concelhos estudados. Devido ao seu relevo acidentado com altas montanhas e vales profundos, a acessibilidade aos aglomerados populacionais torna-se bastante difícil. A seca constitui um problema para o desenvolvimento das ilhas, embora surjam alguns vales com plantações de banana, papaia, coco, milho e feijão.

A educação em Cabo Verde foi considerada como pilar primordial de desenvolvimento. Nesta ótica, os sucessivos Governos não pouparam esforços para investir nesse setor (Cabo Verde, 2016) e ainda o plano estratégico para a educação (Cabo Verde, 2017 p.18) refere que "A alocação para educação tem estado em volta dos 5-6\% do PIB, e a alocação do orçamento de Estado entre 23-27\%. Isto reflete a prioridade dada à educação".

A Educação pré-escolar, enquanto direito das crianças e uma fase muito importante para o desabrochar das suas potencialidades e importante para o sucesso das aprendizagens das crianças, precisa ser estudada na nossa realidade com intuito de melhor conhecer o subsistema e identificar as dificuldades, os avanços e as perspetivas futuras. Assim, definimos como perguntas de partida do estudo: 


\section{Fism Eutlatato}

ISSN: 1984-6444 | http://dx.doi.org/10.5902/1984644439110

Em Cabo Verde tem-se vindo a apostar na construção progressiva de Jardinsde-Infância com infra-estruturas adequadas e recursos cada vez mais apropriados (a maioria por iniciativa das Câmaras Municipais), de modo a diminuir o problema que abrange uma grande dimensão (por motivos relativos aos fatores inerentes ao próprio país: problemas económicos das famílias das crianças, pouco tempo disponível para as crianças de modo a assegurarem uma profissão, serviços públicos carecem de qualidade, recursos e pessoal docente desqualificado, papel secundário da mulher e criança na sociedade, violência nas suas diversas formas, doenças sexualmente transmissíveis, ...): não acompanhamento e abandono das crianças do sistema educativo. Em todos os Jardins-de-Infância, existe uma orientadora/ monitora (consoante as suas habilitações académicas) responsável por um grupo de crianças (uma sala).

Em Cabo Verde ainda não existe uma política relativa ao sector do pré-escolar e subsequentemente, contudo a partir de 2005 a Universidade de Cabo Verde e o Instituto Pedagógico de Cabo Verde (IPCV) criaram os primeiros cursos de licenciatura e de nível médio, respetivamente. Deste modo, as monitoras com um nível académico variado, entre a $4^{\circ}$ e o $12^{\circ}$ ano, (mas com uma formação específica de 10 meses ministrados pelo Instituto Pedagógico de Cabo Verde) e as orientadoras (também com um nível académico variado). Assim falta-Ihes habilitações básicas para suportar a sua prática, reconhecimento profissional, tanto a nível de escalão como de remuneração.

\section{A Formação dos Agentes do pré-escolar:}

A seguir analisaremos vários quadros que demonstram a evolução da formação dos agentes da educação pré-escolar, levando em conta as instituições, os efetivos e tipos de curso oferecidos 


\section{THEM Gitlbapat

ISSN: 1984-6444 | http://dx.doi.org/10.5902/1984644439110

Quadro 4: Alunos matriculados no curso de Capacitação em educação de infância No Centro de Ensino de Assomada

\begin{tabular}{|c|c|c|}
\hline $\begin{array}{l}\text { Anos } \\
\text { letivos }\end{array}$ & $\begin{array}{l}\text { Número de orientadores } \\
\text { matriculados }\end{array}$ & Observações \\
\hline & Capacitação de 10 meses & \multirow{3}{*}{$\begin{array}{l}\text { Essa formação de capacitação tem a finalidade de ajudar as } \\
\text { orientadoras nos aspetos sobre a psicologia do } \\
\text { desenvolvimento e da aprendizagem, planificação e avaliação } \\
\text { dentre outras disciplinas básicas para a educação de infância. }\end{array}$} \\
\hline $2010 / 2011$ & 30 & \\
\hline Total & 30 & \\
\hline
\end{tabular}

Fonte: Construção própria com dados da secretaria da referida escola

Pela análise do quadro 4 é possível verificar a existência de cursos de capacitação de curta duração (10 meses) em Escola Secundária e de formação profissional privada, isto mostra que devido à necessidade de pessoal formado ou capacitado na área de educação de infância, outras entidades tomaram a iniciativa de formação.

Quadro 5: Alunos matriculados no curso de educação de infância na Escola de Formação de Professores do Ensino Básico do Mindelo- EFPEBM

\begin{tabular}{|c|c|c|c|c|c|}
\hline \multirow[t]{2}{*}{ Anos letivos } & \multicolumn{3}{|c|}{ Número de Formandos matriculados } & \multirow{2}{*}{$\begin{array}{l}\text { Número de } \\
\text { Formandos } \\
\text { aprovados }\end{array}$} & \multirow{2}{*}{$\begin{array}{l}\text { Número de } \\
\text { formandos } \\
\text { reprovados }\end{array}$} \\
\hline & Inicial $^{2}$ & Capacitação ${ }^{3}$ & Exercício $^{4}$ & & \\
\hline 98 a 2001 & 25 & & & 22 & 3 \\
\hline 2005 a 2008 & & & 37 & 37 & 0 \\
\hline 2006 a 2009 & & & 32 & 25 & 7 \\
\hline 2007 a 2010 & & & 61 & 50 & 11 \\
\hline 2008 a 2011 & & & 26 & & 26 \\
\hline Total & 25 & & 156 & 134 & 22 \\
\hline Total geral & & 181 & & & \\
\hline
\end{tabular}

Fonte: Construção própria com dados da secretaria da referida escola

Pela análise deste quadro (5) fica evidente que na Escola de Formação de Professores do Ensino Básico do Mindelo, não se ministrou a formação de curta duração, e que o número de formandos em exercício é superior à todas as escolas, já que esta escola foi a pioneira em ministrar o curso de nível médio de educadores-deinfância em Cabo Verde. 


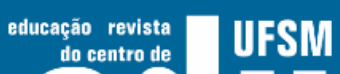 outuará

ISSN: 1984-6444 | http://dx.doi.org/10.5902/1984644439110

Quadro 6: Alunos matriculados no curso de educação de infância na Escola de Formação de Professores do Ensino Básico de Assomada- EFPEBA

\begin{tabular}{|l|l|l|c|}
\hline $\begin{array}{l}\text { Anos } \\
\text { letivos }\end{array}$ & \multicolumn{3}{|l|}{ Número de FORMANDOS matriculados } \\
\hline & Inicial & $\begin{array}{l}\text { 5Curso especial de formação monitores } \\
\text { de infância }\end{array}$ & Exercício \\
\hline $\mathbf{2 0 0 8 - 2 0 1 1}$ & & & 60 \\
\hline $\mathbf{2 0 0 9}-\mathbf{2 0 1 2}$ & & & 32 \\
\hline $\mathbf{2 0 1 2 / 2 0 1 3}$ & & 17 & 25 \\
\hline Total & & 17 & 117 \\
\hline
\end{tabular}

Fonte: Construção própria com dados da secretaria da referida escola

O quadro 6 expressa a particularidade da oferta de um curso especial de formação de Monitores de Infância que se iniciou em 2012/2013 com um total de 17 formandas, curso esse criado para dar resposta as necessidades de um concelho da ilha de Santiago, isso também mostra que devido ao perfil variado dos formandos fica difícil montar planos de estudos. É interessante também ver que esta escola de formação apostou mais na formação em exercício abarcando um total de 117 monitores e orientadores de vários concelhos de Santiago Norte.

Quadro 7: Alunos matriculados no curso de educação de infância na Escola de Formação de professores do Ensino Básico Hermínia Cardoso da Praia- EFPEB-HC

\begin{tabular}{|c|c|c|c|c|c|}
\hline \multirow[t]{2}{*}{ Anos letivos } & \multicolumn{3}{|c|}{ Número de Formandos matriculados } & \multirow{2}{*}{$\begin{array}{l}\text { Número de } \\
\text { Formandos } \\
\text { aprovados }\end{array}$} & \multirow{2}{*}{$\begin{array}{ll}\text { Número } & \text { de } \\
\text { formandos } & \\
\text { reprovados } & \\
\end{array}$} \\
\hline & INICIAL & CAPACITAÇÃO & EXERCICIO & & \\
\hline \multicolumn{6}{|l|}{98 a 2001} \\
\hline 2005 a 2008 & & 96 & & 96 & \\
\hline 2006 a 2009 & 24 & & 27 & 47 & 4 \\
\hline 2007 a 2010 & 35 & & & 25 & $\begin{array}{lr}\text { (outros } & \text { cinco } \\
\text { desistiram } & \text { ou } \\
\text { anularam } & \text { a } \\
\text { matrícula.) } & \end{array}$ \\
\hline 2008 a 2011 & & & 35 & & \\
\hline 2009 a 2012 & & & 29 & & \\
\hline Total & 79 & 96 & 91 & 72 & 9 \\
\hline
\end{tabular}

Fonte: Construção própria com dados da secretaria da referida escola.

O Quadro anterior demonstra que escola de Formação de Professores do Ensino Básico da Praia iniciou o curso de orientadores de infância em exercício desde 


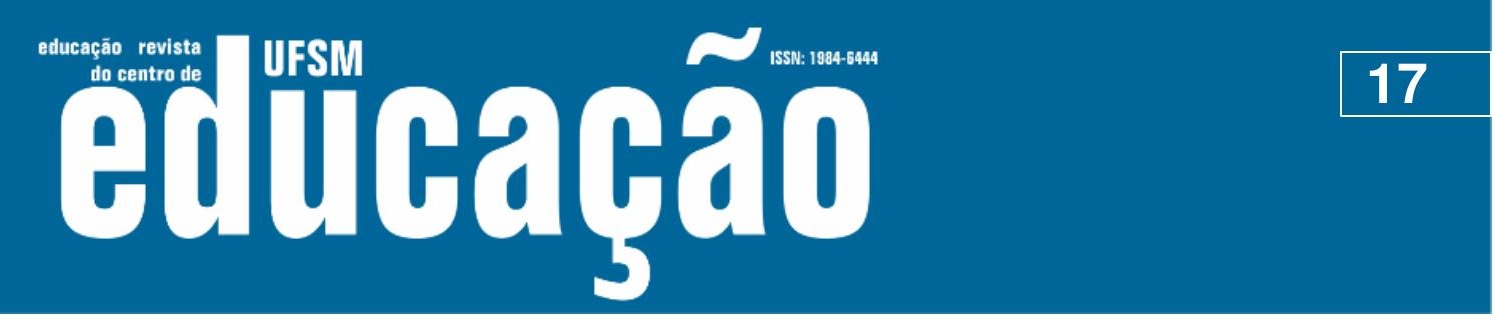

ISSN: 1984-6444 | http://dx.doi.org/10.5902/1984644439110

Quadro 10: Problemas a nível institucional, operacional e legislativo na Educação Pré-escolar

\begin{tabular}{|l|l|}
\hline $\begin{array}{l}\text { Nível } \\
\text { Institucional }\end{array}$ & $\begin{array}{l}\text { Falta de articulação entre os diferentes departamentos e dos programas } \\
\text { destinados às crianças; deficiente articulação entre a educação pré-escolar e } \\
\text { o ensino básico; assimetrias no acesso à educação pré-escolar; rede de } \\
\text { jardins caótica, insuficientemente integrada na realidade geográfica e social; } \\
\text { deficientes mecanismos de acompanhamento pedagógico e do } \\
\text { funcionamento dos jardins; }\end{array}$ \\
\hline Nível Operacional & $\begin{array}{l}\text { Deficiente animação comunitária, intervenção concertada junto das famílias } \\
\text { e ao maior envolvimento na defesa das crianças; deficiências graves na } \\
\text { gestão de um grande número de jardins-de-infância. }\end{array}$ \\
\hline Nível Legislativo & $\begin{array}{l}\text { Insuficiente regulamentação das disposiçães legais referentes a menores e } \\
\text { de mecanismos eficazes para a sua aplicabilidade; Necessidade de revisão } \\
\text { da Lei de Bases do Sistema Educativo, em termos de definição das } \\
\text { responsabilidades do Ministério da Educação na educação pré-escolar, da } \\
\text { sua integração no sistema educativo, da clarificação de competências dos } \\
\text { intervenientes, em particular na transferência de responsabilidades e de } \\
\text { recursos para os concelhos. }\end{array}$ \\
\hline
\end{tabular}

Fonte: Cabo Verde, 2002

Não obstante a educação Infância como primeira etapa no processo da educação ao longo da vida (Lei 103/ll1/90 de Cabo Verde) e lei-quadro da educação pré-escolar de Portugal (lei nº 4/97 de 10 de fevereiro) deve merecer muita atenção dos decisores políticos e não só, daí que estudos têm demonstrado que os primeiros anos de vida da criança são decisivos para o seu desenvolvimento físico, mental e emocional, sendo inegável o papel decisivo da educação da infância na construção de estruturas fundadoras de suporte às aprendizagens futuras promotoras da aquisição de conhecimentos, capacidades e atitudes ulteriores.

\section{Apresentação e Discussão de Resultados}

Ciente de que a educação pré-escolar é uma das fases de sustentabilidade de todas as outras que vem a seguir, e porque é ali que se desenvolvem determinadas competências que vão servir de base para o desenvolvimento da aprendizagem durante toda a vida, não se pode ignorar a sua qualidade e a sua contribuição para crescimento de forma integral de todas as crianças.

Foi notável ver a evolução da educação em Cabo Verde e especial a educação préescolar pelos passos que deu, desde não existência até a afirmação do subsistema mesmo passando por diversas barreiras. 


\section{T usm

ISSN: 1984-6444 | http://dx.doi.org/10.5902/1984644439110

A partir da análise documental realizada verificamos que houve muitos esforços para que a educação pré-escolar se afirmasse mesmo indo contra alguns princípios como por exemplo igualdade de oportunidades como foi o caso do artigo $72^{\circ}$ da lei nº103/III/90 de 29 de dezembro na nova redação dada pela lei $n$ ำ113/V/99 de 18 de Outubro que incentivou a frequência da educação pré-escolar durante 18 anos dizendo que «ingressa no ensino básico com 6 anos as crianças que tiverem frequentado pelo menos dois anos da educação pré-escolar caso contrário ingressaria com 7 anos». A nível das dificuldades enfrentadas pela educação pré-escolar o plano estratégico para a educação (MEVRH, 2002) identificou que existe «Baixo nível de qualificação das monitoras/ orientadoras; material didático insatisfatório; enquadramento e acompanhamento da área deficiente, condicionando a preparação para o ensino básico.

No questionário aplicado aos profissionais de educação de infância verificamos que existe um público com pouca formação desejada na área, uma vez que apenas 2,4\% possui uma formação Superior em educação de infância e 23,2\% possui uma formação média ou profissional. Fica evidente que existe um público com habilitações Baixas ou ainda com apenas o ensino secundário, e ainda $27,6 \%$ é considerado educador de infância. Conforme se pode ver no gráfico 1 e 2, respetivamente:

Gráfico 1: Habilitações Literárias

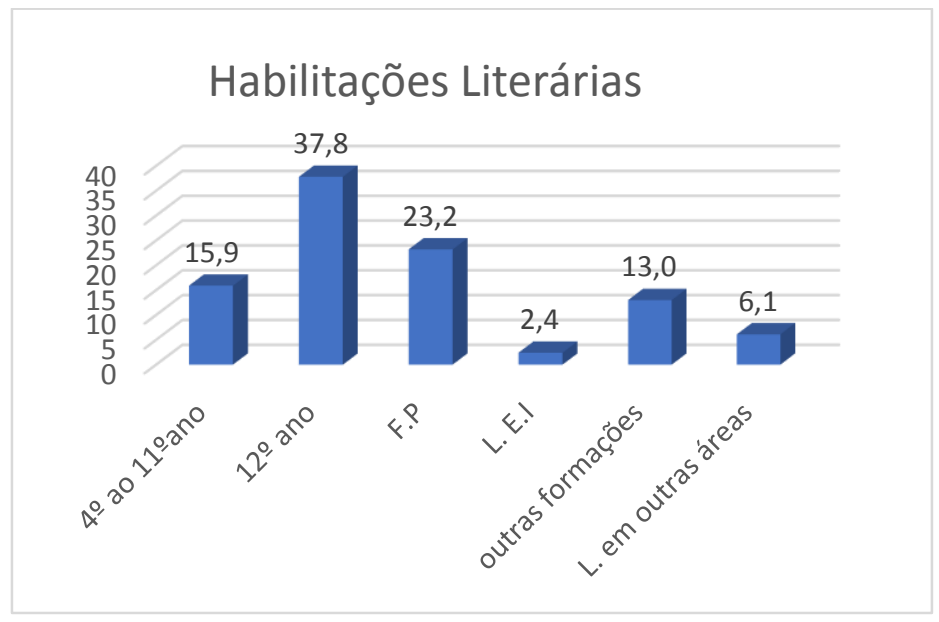

Fonte: Construção Própria com dados do questionário 


\section{$\sim$

ISSN: 1984-6444 | http://dx.doi.org/10.5902/1984644439110

Gráfico 2: Categoria Profissional

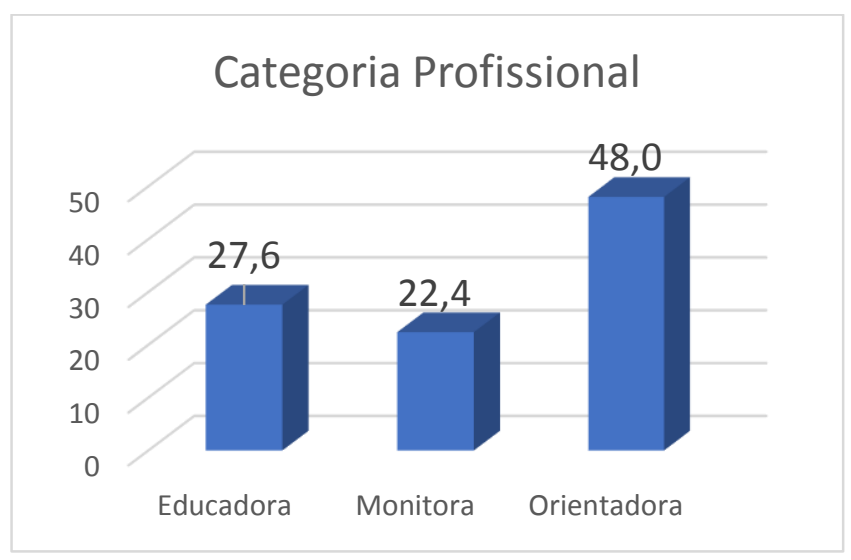

Fonte: Construção Própria com dados do questionário

$\mathrm{Na}$ entrevista aos diversos atores da sociedade civil ficou patente que a nível do pessoal docente existem vários constrangimentos como se pode verificar na tabela 1 abaixo:

Tabela 3:Constrangimentos a nível do pessoal docente

\begin{tabular}{l|l}
\hline Pessoal docente & F \\
\hline Pessoal docente sem qualificação & 8 \\
Falta de enquadramento do pessoal docente formado e os do terreno & 8 \\
Demasiada atenção ao ensino superior em detrimento deste subsistema & 1 \\
Dificuldade de Montagem de planos curriculares de formação & 1 \\
\hline
\end{tabular}

Fonte: construção própria com dados da entrevista.

Ainda foi possível perceber a partir dos questionários e entrevistas, que a medida política de aceitar todas as crianças matricularem no ensino básico independentemente de frequentarem os jardins-de-infância afetaram a frequência normal das crianças aos jardinsde-infância, como se pode notar nas expressões dos nossos entrevistados TME1 afirma :

No ano seguinte algumas crianças não foram para os jardins principalmente no primeiro trimestre e não foram para os jardins. A TME2 conta As crianças continuaram a ir ao jardim. A TME3 descortina dizendo: Essa lei trouxe outras desvantagens aos jardins. Os pais deixaram de pagar os jardins e as crianças mudam constantemente de jardim. 


\section{N Wrsm

ISSN: 1984-6444 | http://dx.doi.org/10.5902/1984644439110

Para confrontar as informações questionamos aos profissionais de infância e vejamos o que responderam no gráfico 3 abaixo:

Gráfico 3 - efeitos do decreto lei 꾼/2008 de 24 de outubro.

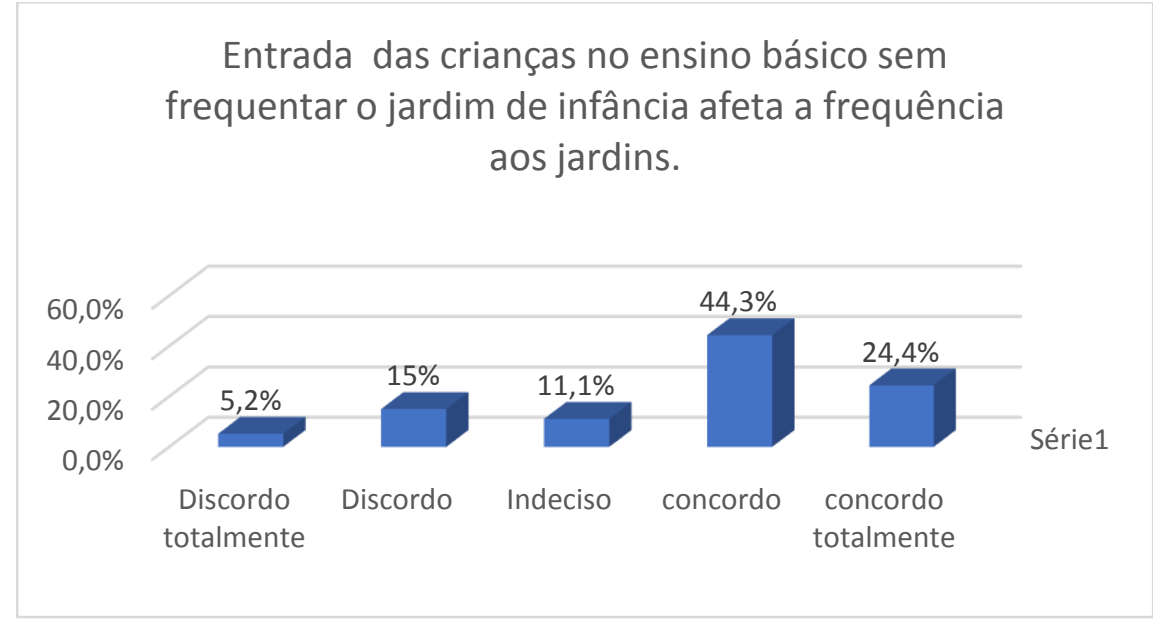

Fonte: construção própria com dados do questionário.

Conforme o gráfico anterior, 44,3\% dos inquiridos concordam que essa medida política afetou a frequência das crianças e $24,4 \%$ concorda totalmente, por conseguinte apenas $15 \%$ e 5,2 discorda e discorda totalmente, respetivamente.

No que tange à medida de transferir os profissionais de educação de infância formados para o ensino básico os entrevistados são da opinião que isso irá dificultar o desenvolvimento da educação pré-escolar e também do ensino básico conforme as palavras dos técnicos TME1: "Esse recrutamento afetou-nos muito porque as que tinham formação davam suporte as que não tinham". E ainda acrescenta "Poderá penalizar a educação" TME2 e TME3 não tem dúvidas e afirmam "É claro que essa saída vai influenciar a qualidade tanto da educação pré-escolar como no básico".

Ora, com a análise documental percebemos também que o Estado se responsabiliza pela definição de políticas e criar as condições para a sua implementação, apoiando iniciativas públicas e privadas relativamente à criação de jardins-de-infância e a fiscalização do seu funcionamento. Particularmente, quando fala das atribuições dos coordenadores no artigo 4ํำ do decreto-lei $n 05 / 2001$ de 1 de fevereiro alínea i) "cooperar com a Direção geral do ensino básico e secundário 


\section{Aithoapẫ \\ 3}

ISSN: 1984-6444 | http://dx.doi.org/10.5902/1984644439110

(DGBES) e a inspeção Geral na supervisão do cumprimento das orientações emanadas superiormente"

Por outro lado, ficou evidente também nos documentos oficiais como o guia de atividades curriculares para o jardim-de-infância (2001) que a "criação de espaços sem condições prejudicará o desenvolvimento das crianças.

Ainda o Art 5ำ ponto 2 do decreto lei nำ/2001 de 1 de fevereiro diz « todas as instituições que fazem parte da rede pré-escolar devem ser previamente oficializadas pelos serviços competentes do departamento governamental responsável pela educação, através da concepção de um alvará isso é contrario aquilo que nós observamos no gráfico 4.

Gráfico 4 - o jardim-de-infância onde trabalha possui alvará?

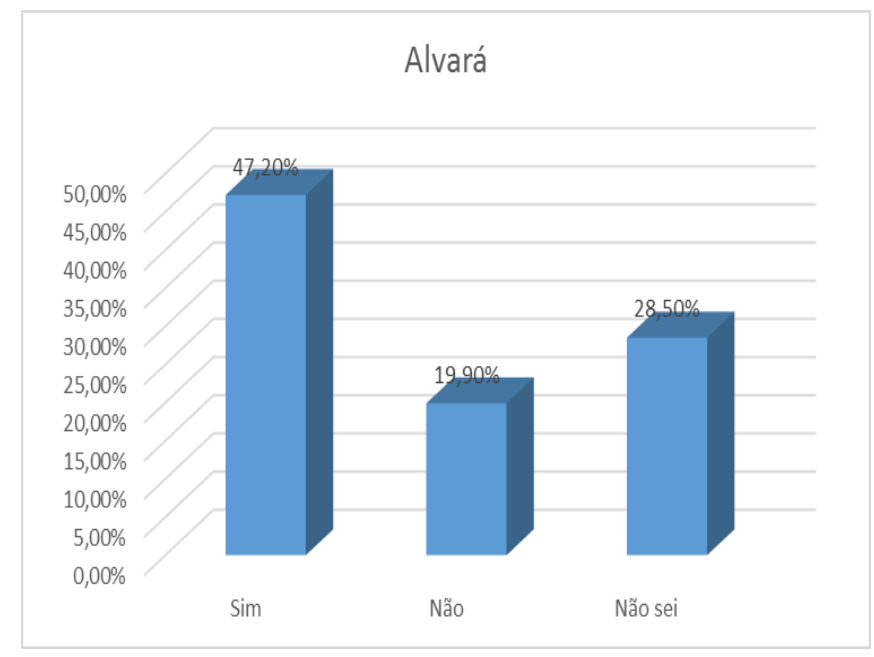

Fonte: Construção Própria com dados do questionário

O gráfico 4 nos salienta que 47,2\% dos jardins-de-infância dos nossos inquiridos possui o alvará de funcionamento, 19, 9\% dos jardins-de-infância não possui, $28,5 \%$ dos inquiridos dizem que não sabem se o jardim de infância possui o alvará e 4,4\% são aqueles que não responderam a essa questão.

No que concerne às práticas pedagógicas, os resultados apontam para o facto de nossos inquiridos concordarem que devem ser eles a dirigir e a decidir sobre o que as crianças fazem $45 \%$ e $9 \%$ concordam e concordam totalmente conforme se pode ver no gráfico 5. Isto vai contra o que o guia de atividades para a educação pré-escolar 


\section{Tusm

ISSN: 1984-6444 | http://dx.doi.org/10.5902/1984644439110

p.14 diz que se deve "Utilizar metodologias globalizantes centradas na criança". E isso permitirá que a criança descubra o meio que a cerca e tenha uma aprendizagem significativa.

Gráfico 5 - Direção e decisão sobre as atividades das crianças

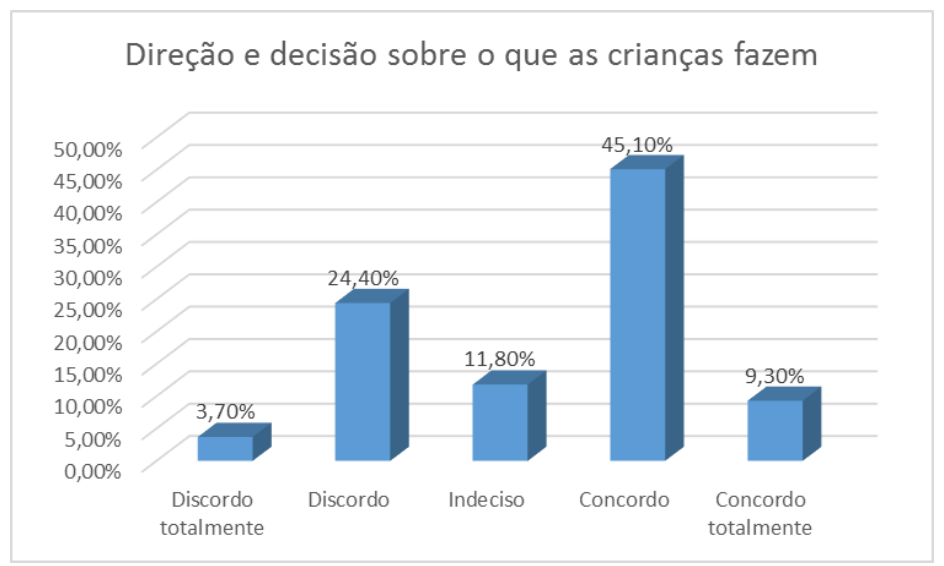

Fonte: Construção própria com dados do questionário.

Quanto às formações que devem possuir, os nossos inquiridos são de opinião que todo profissional deve ter uma formação universitária, conforme podemos observar no gráfico a seguir:

Os educadores de infância devem ter preparação universitária e experiência supervisionada.

Gráfico 6 - Os educadores de infância devem ter preparação universitária e experiência supervisionada.

\section{Os educadores de infancia devem ter preparação universitaria e experiência supervisionada.}

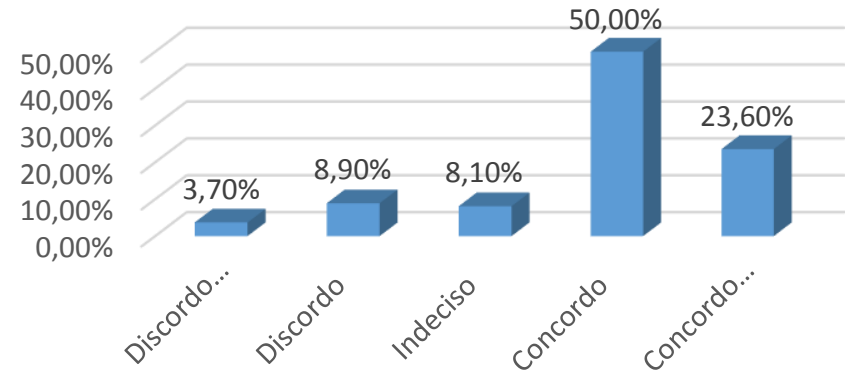

Fonte: Construção própria com dados do questionário 


\section{Aillbapẫ \\ 3}

ISSN: 1984-6444 | http://dx.doi.org/10.5902/1984644439110

Embora a maioria dos nossos inquiridos não possuírem formação na área, consideram importante ter uma formação universitária e um estágio antes de ingressarem na vida profissional. Fica evidente pelas respostas que $73,6 \%$ (se juntarmos os que concordam e os que concordam totalmente) acham essencial ter uma formação especializada na área em que labuta.

Isto também vai de acordo com aquilo que comunga a o decreto legislativo $n$ ำ2/2010 de 7 de maio que diz que "a formação dos agentes do pré-escolar também deve ser superior".

Este fato é questionável, sendo que desde do ano letivo 2012/2013 terminaram todas as formações de educadores de infância no país. Como é que se vai fazer isso?

\section{Conclusões}

Cabo Verde teve o seu primeiro Ministério da Educação e Cultura no Governo de transição para a Independência (janeiro a Julho de 1975). A partir desta data até ao momento, a educação em Cabo Verde tem vindo a evoluir de uma forma gradual e consciente, contornando sistematicamente “ (...) os desafios [para o sector educativo], exigindo o aprofundamento das reformas, a alteração ou a afirmação de claras orientações estratégicas e uma maior unidade de princípios para se conseguir um desenvolvimento equilibrado e sustentável para todo o sistema." (Cabo Verde, 2003, p.11).

Acompanhando o movimento de massa de consciencialização sobre a importância e o papel da educação no desenvolvimento da sociedade, Cabo Verde tem-se tornado num país regenerador e partidário acerca das questões que a educação abrange, em todos os seus sectores, desde a educação de infância à extraescolar.

Não obstante, a criança tem ocupado um lugar de destaque no quadro dos programas sociais levados a cabo por departamentos Governamentais, organizações diversas da sociedade civil, por iniciativas de carácter nacional, local e individual, de modo a promover, cada vez mais, o desenvolvimento integral da criança. 


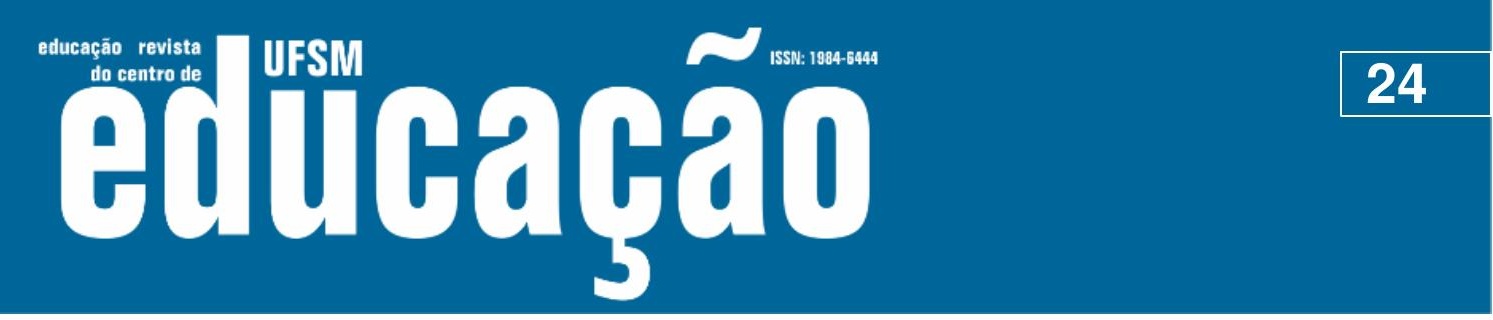

ISSN: 1984-6444 | http://dx.doi.org/10.5902/1984644439110

Neste sentido que consideramos que este estudo poderá trazer alguns benefícios para Cabo Verde, na medida em que durante esta pesquisa foram destacados os benefícios da independência para a educação, a evolução da educação pré-escolar após independência, e ainda o estudo frisou a infância como um dos períodos marcantes para vida do ser humano.

Consequentemente durante este estudo foi considerado pelos entrevistados que a educação pré-escolar tem tido uma evolução lenta no nosso país e que só a partir 1990, se foram desenhando políticas de expansão. No entanto, nos últimos anos, assistiu-se um grande esforço de valorização do subsistema sobretudo com a preocupação que o estado tem na formação do pessoal docente desta área conforme demonstrada no decreto lei no 2/2010 de 7 de maio.

Entretanto a partir dos questionários ficou patente que é necessário investir na formação do pessoal docente, uma vez que a maioria dos nossos inquiridos consideram que o pessoal afeto à educação pré-escolar deve possuir uma formação universitária, que algumas medidas políticas desfavorecem a educação pré-escolar como por exemplo a saída do pessoal formado para o Ensino Básico bem como a lei que permite que todos tem acesso ao ensino básico com 6 anos independentemente da frequência à Educação Pré-escolar, foi possível perceber que os jardins de infância funcionam sem alvará o que permite que alguns espaços funcionem sem condições, no que tange a prática pedagógica dos profissionais ficou evidente que alguns profissionais tem uma prática inadequada uma vez que possuem uma metodologia centrada nelas em vez centrar nas crianças.

Apesar da sensibilização para esta etapa educativa, concluímos que há necessidade de ação por parte do Estado, e outras entidades e investir na educação pré-escolar como fator de desenvolvimento sustentável.

\section{Bibliografia}

BARDIN, Laurence. Análise de conteúdo. Lisboa: Edições 70, 1995.

BOGDAN, Robert. \& Biklen, Sari, Investigação Qualitativa em Educação. Uma Introdução à Teoria e aos Métodos. Porto: Porto Editora, 1999. 


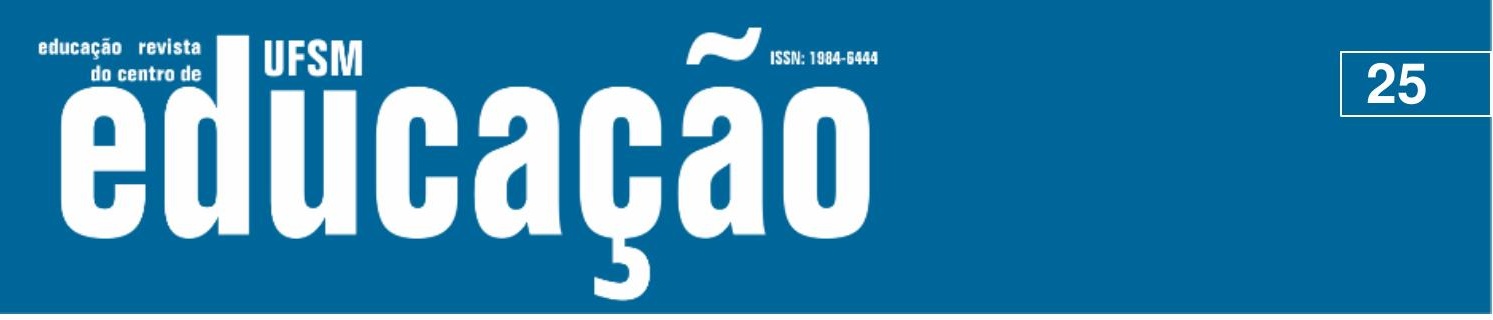

ISSN: 1984-6444 | http://dx.doi.org/10.5902/1984644439110

CABO VERDE, Assembleia Nacional. Constituição da República. (4. Edição) Praia, 2010.

CABO VERDE. I serie do Boletim oficial $\mathbf{n} \div \mathbf{4}$ /2001 de 1 de fevereiro. Normas e orientações pedagógicas para a educação pré-escolar.

CABO VERDE. I serie do Boletim oficial n5/2001 de 1 de fevereiro: perfil e atribuição do coordenador do pré-escolar.

CABO VERDE. I serie, Boletim oficial n43 de 24 de novembro de $2008 \operatorname{art}^{\circ} 1^{\circ}$. ingresso no ensino básico.

CABO VERDE, Ministério de Educação e Valorização dos Recursos Humanos, Lei n.o 103/III/90 de 29 de dezembro. Lei de Bases do Sistema Educativo, 1990.

CABO VERDE, Ministério de Educação e Valorização dos Recursos Humanos. Alteração Lei no 113/V/99 de 13 de outubro. Lei de Bases do Sistema Educativo, 1999.

CABO VERDE, Ministério de Educação e Valorização dos Recursos Humanos (2002).

Plano Nacional de Ação de Educação para Todos. Praia, 2002.

CABO VERDE,Ministério de Educação e Valorização dos Recursos Humanos. Plano Estratégico para a Educação. Praia, 2003

CABO VERDE, Ministério de Educação e Valorização dos Recursos Humanos. Guia de atividades curriculares para os jardins de infância. Praia, 2003

CABO VERDE, Ministério de Educação e Valorização dos Recursos Humanos. Decreto Legislativo n. 2 de 2004. Estatuto do Pessoal Docente, 2004.

CABO VERDE, Ministério de Educação e Desporto, Decreto-Legislativo no 2/2010 de 7 de maio. Lei de bases do sistema educativo, 2010.

CABO VERDE, Ministério da Educação. Plano Estratégico para a Educação, Praia, 2017.

CABO VERDE, Ministério da Educação. Principais indicadores da Educação. Praia, 2017.

COHEN, Louis; MANION, Lawrence, Métodos de Investigação Educativa. Madrid. Editorial La Muralla, 1990.

LISBOA, Ministério de Educação. Decreto. Lei no 241/01 de 30 de agosto. Lisboa: DEB

PEIXOTO, Ana Maria, A criança e o conhecimento do mundo: atividades laboratoriais em ciências físicas. Lisboa: editorial Novembro, 2008. 


\section{uss \\ 18SN: $1984-6444$

ISSN: 1984-6444 | http://dx.doi.org/10.5902/1984644439110

PINA, Vera Duarte Lobo. Cabo Verde e a Educação: ganhos e desafios. Meta avaliação, Rio De Janeiro, vol.1, oㅜ, p.375-385, set./dez. 2009.

VARELA, Bartolomeu, A relevância da educação pré-escolar nas opções de políticas do estado de Cabo Verde. Praia: Rede nacional de educação para todos, 2015.

VASCONCELOS, Teresa. Exame Temático da OCDE à Educação e Cuidados para a Infância: Relatório Comparativo Internacional. Da Construção do Edifício ao Lançamento de Pontes para o Futuro. Infância e Educação: Investigação e Práticas. 2001.

\section{Correspondência}

Catarina Fernandes Delgado - Universidade de Cabo Verde - Palmarejo, 7600, Praia, Cabo Verde.

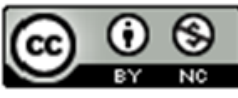

This work is licensed under a Creative Commons Attribution-NonCommercial 4.0 International (CC BY-NC 4.0)

\section{Notas}

\footnotetext{
${ }^{1}$ Cabo Verde tomou Independência de Portugal em 1975

2 formação média de três anos para todos interessados habilitados com o $10^{\circ}$ ano.

${ }^{3}$ formação de curta duração (10 meses) de apoio a prática pedagógica para todas as orientadoras em exercício de funções.

${ }^{4}$ formação média para as orientadoras e monitoras com pelo menos $10^{\circ}$ ano de escolaridade em exercício de funções.

${ }^{5}$ Esse curso especial foi destinado apenas as orientadoras de educação de infância do concelho de São Miguel com apoio da Bornefonden. E foi desenvolvido em duas fases (a $1^{\mathrm{a}}$ fase para aquelas com menos habilitações literárias com intuito de elevar o nível académico e a segunda fase para todas as orientadoras que não tinham nenhuma capacitação na área incluído as que que frequentaram a primeira fase).
} 